\title{
Refurbishing Fæstningens Materialgård: A Heritage
}

\section{Complex}

Torben Valdbjørn Rasmussen

Department of Construction and Health, Danish Building Research Institute, Aalborg University, Copenhagen 2450, Denmark

\begin{abstract}
Fæstningens Materialgård is a listed complex located in downtown Copenhagen. The refurbishment of the listed complex was studied to provide knowledge on how a process for refurbishing heritage buildings can be carried out successfully, as refurbishment of heritage buildings is often a complicated process. The process shows how to choose, evaluate and implement measures creating synergy between the interests of preserving heritage values and to develop affordable refurbishment that meets the requirements for the future use of the building. The refurbishment followed included restoration, energy upgrading and refurbishment of the individual buildings that make up the listed complex. The process focuses on the cooperation and dialogue between the parties involved. Fæstningens Materialgård is a case study where the Heritage Agency, the Danish Working Environment Authority and the owner as a team cooperated in identifying feasible refurbishment measures. Through the process the owner was supported by architects and engineers. Focus is put on how, to identify potential energy savings and, to decide on energy upgrading measures when refurbishing and restoring listed buildings. The refurbished Fæstningens Materialgård is visualized in photos.
\end{abstract}

Key words: Building, heritage, refurbishment.

\section{Introduction}

Fæstningens Materialgård is a listed complex and as such assessed to be among the best or most characteristic of its kind and period. A total of $13 \%$ of all buildings in Denmark are assessed to be heritage buildings, and given a status as listed or worthy of preservation. Approximately, 9,000 buildings are listed and approximately 350,000 buildings have been assessed as being worthy of preservation. The overall purpose of listing a building is to ensure that the building is changed as little as possible.

Buildings considered worthy of preservation are designated by using the SAVE (Survey of Architectural Values in the Environment) method [1], and protected on a regional level by local authorities. Listed buildings are protected by the National Heritage Agency.

The listed complex, Fæstningens Materialgård, is located at Frederiksholms Canal which was dug out in

Corresponding author: Torben Valdbjørn Rasmussen, Ph.D., senior researcher, research fields: innovation and construction. E-mail: tvr@sbi.aau.dk.
1681 in the western part of downtown Copenhagen. The ground area of the complex originated as an infill for the expansion of Copenhagen, which included the construction of the ramparts of Vester Vold.

The history of the listed complex goes back to the 17th/18th centuries when the old royal materials yard had to be replaced by a new one. The complex was initiated in 1740 with a new, very distinguished, brick residence for the supervisor. The architect of the building is not known with certainty, but is assumed to be the national building master J.C. Krieger. The buildings form a single listed complex surrounding a courtyard, as shown in Fig. 1, consisting of brick buildings with red-tiled roofs, yellow lime-washed facades, green-painted doors and gates and white-painted windows. Only the original warehouse of the complex is built as a half-timbered construction.

The use of the individual buildings of the complex has changed several times through its history. Recently, the buildings have been used for different office-type functions. In 2007, the complex was examined 


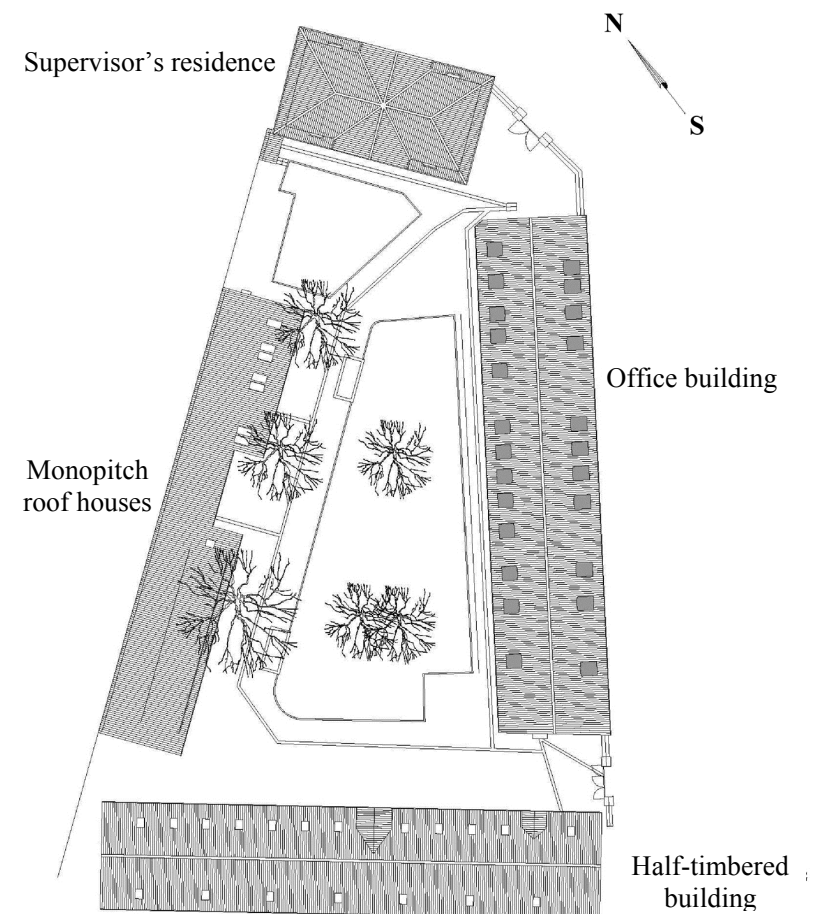

Fig. 1 Site plan of the listed complex, Fæstningens Materialgård.

identifying heritage values. At that time, it was stated that the condition of the listed complex was strongly affected by the many refurbishments of the buildings which did not respect the values of the listed complex. However, it does not appear to have caused serious settlement of the foundations.

Like Fæstningens Materialgård, most listed buildings in Denmark are privately owned. Despite the private ownership, the Heritage Agency is responsible for and administers the listed buildings. All building work that goes beyond normal maintenance requires permission from the Heritage Agency. This means that the owner of a listed building must obtain permission from the Heritage Agency to make any changes to the building, including all repairs and restoration work. Therefore, the decision-making processes concerning the refurbishment of listed buildings are carried out in cooperation and dialogue with the Heritage Agency.

The decision-making processes has been followed and is described, in particular its focus is on the cooperation and dialogue between authorities and the owner, Realdania, a Danish real estate society, which implemented the refurbishments of Fæstningens Materialgård. In the case of Fæstningens Materialgård, the Heritage Agency, the Danish Working Environment Authority and Realdania cooperated to identify potential energy savings and to decide on feasible and acceptable energy-upgrading measures for the listed complex. Tightened energy provisions for new buildings require listed buildings to reduce energy consumption for heating and comfort, in order to reduce $\mathrm{CO}_{2}$ emissions, and to ensure that these buildings also in the future can remain part of the attractive private building stock.

The restoration and energy upgrading was initiated in 2007, when Realdania bought the listed complex with the ambition of turning it into offices for renting out. As the owner, it was Realdania's responsibility not only to maintain the listed complex as required by law but also to restore, refurbish and upgrade it. The restored, refurbished and upgraded complex is shown in photos.

\section{The Heritage Values, Preservation Status and Conditions}

The buildings and the courtyard area have status as listed. The listing is based on the Danish Act on Protecting Buildings and the Conservation of Buildings and the Built Environment [2]. The aim of the act is to protect the country's old buildings that are of architectural, cultural or environmental value, including buildings that highlight residential, working and manufacturing conditions as well as other important features of the development of society. When carrying out building work on a listed building, the same techniques and materials should be used that were used to build the original building. Building materials and techniques are characteristic of both the period and the region, both of which are an integral part of the culture of the building, and they are therefore a part of its heritage value. This is especially true of materials and techniques that were developed 
and proven over a long time through experience. If experimental materials or techniques are to be used in a listed building, it should be ensured that they are implemented in such a way that they can be removed again.

Fæstningens Materialgård represents a landmark on the city harbor front. It has a long history and is an example of the expansion of Copenhagen in the late 17 th/early 18 th centuries when the former city ramparts where used for other purposes.

Each of the buildings in the complex has fundamental heritage values. The supervisor's residence, as shown in Fig. 2, is recognized by its representative character and position in the hierarchy of the complex, the hierarchy between the storeys, the rooms and interiors with a mix of historic styles and the joinery detailing. The supervisor's residence is characterized as the "grandest" building in the complex, and there is a desire to expose and enhance the fine, richly furnished interiors. The still-preserved half-timbered building, as shown in Fig. 3, shows the warehouse character of the building, which clearly shows the longitudinal beam construction and rough, simple detailing. The character of the half-timbered warehouse with clear constructions and rough, simple detailing, as well as its close relationship with the courtyard, is to be emphasized and strengthened through the restoration. The office building is recognized for its longitudinal partition walls, distinction between the northern and southern parts of the building, its room structure unity and joinery details (Fig. 4). The conservation of the office building was undertaken to re-establish valuable elements from different periods of alteration and to restore the old room structures. The monopitch roof building, shown in Fig. 5, includes a still-preserved building which shows the original timber construction with very large dimensions. Restoration of the monopitch roof building was undertaken to re-establish the characteristics of the buildings as more or less open "sheds" with clear constructions, few, simple details and a close relationship to the courtyard.

\section{The Process of Refurbishment}

The process followed to restore and to detect feasible refurbishment measures that reduce the energy consumption of the listed complex assumes the

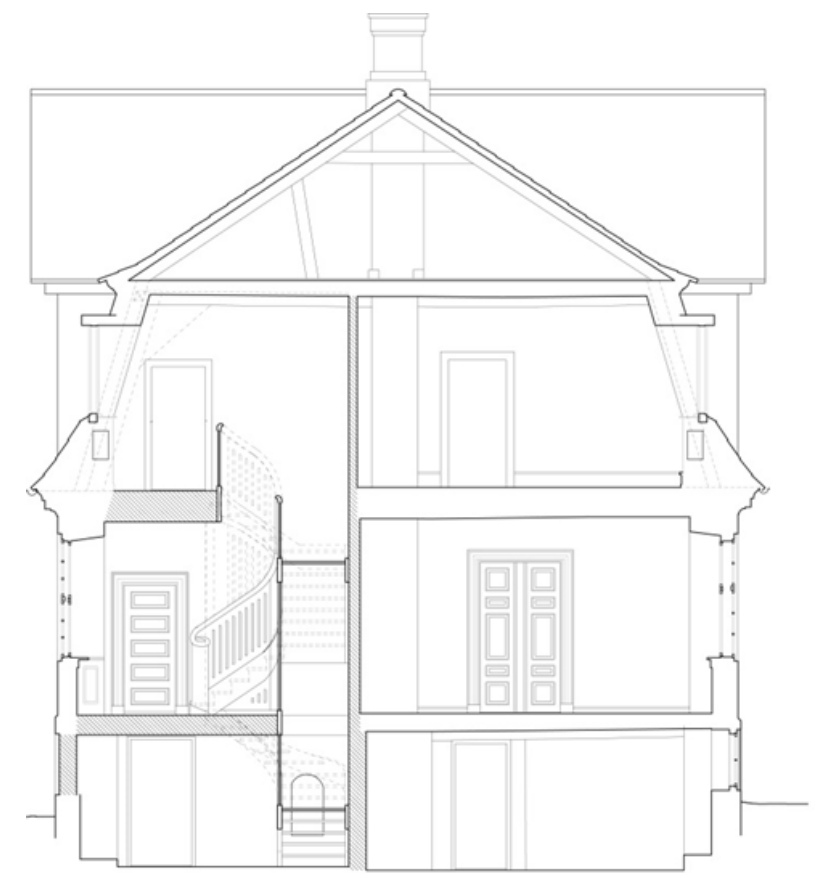

Fig. 2 Structural section of the building which contains the supervisor's residence.

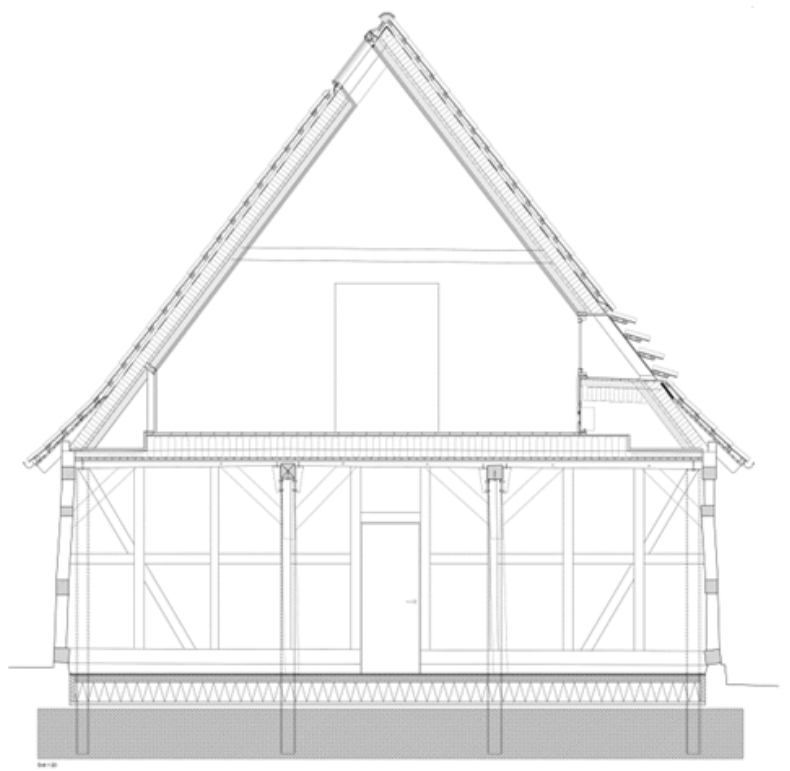

Fig. 3 Structural section of the half-timbered building. 


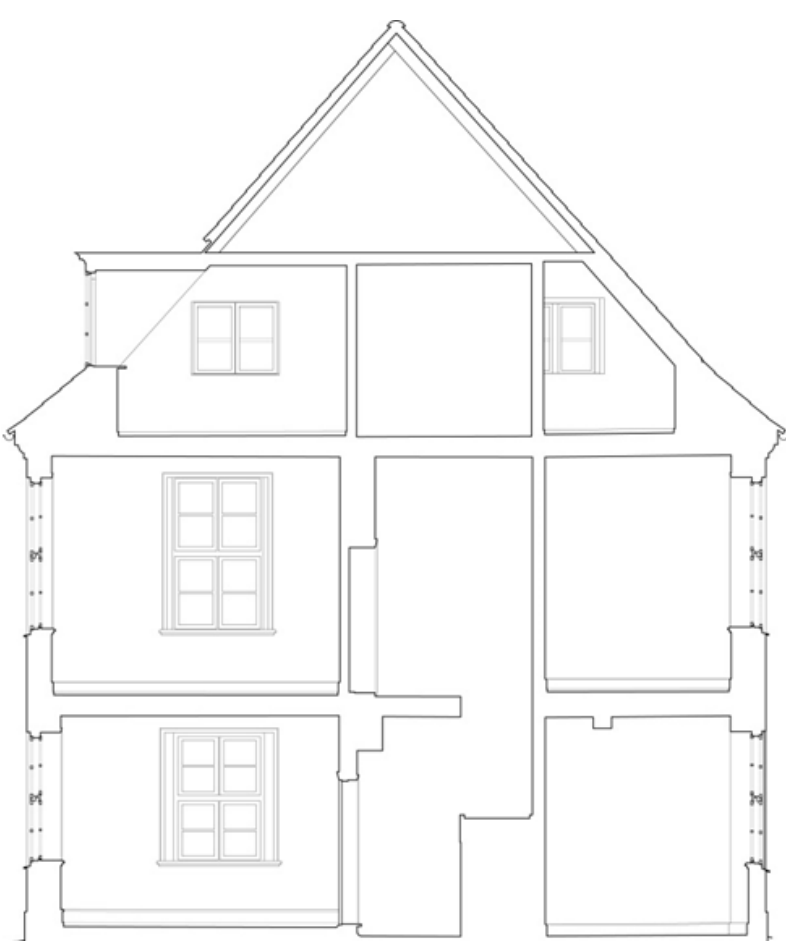

Fig. 4 Structural section of the office building.

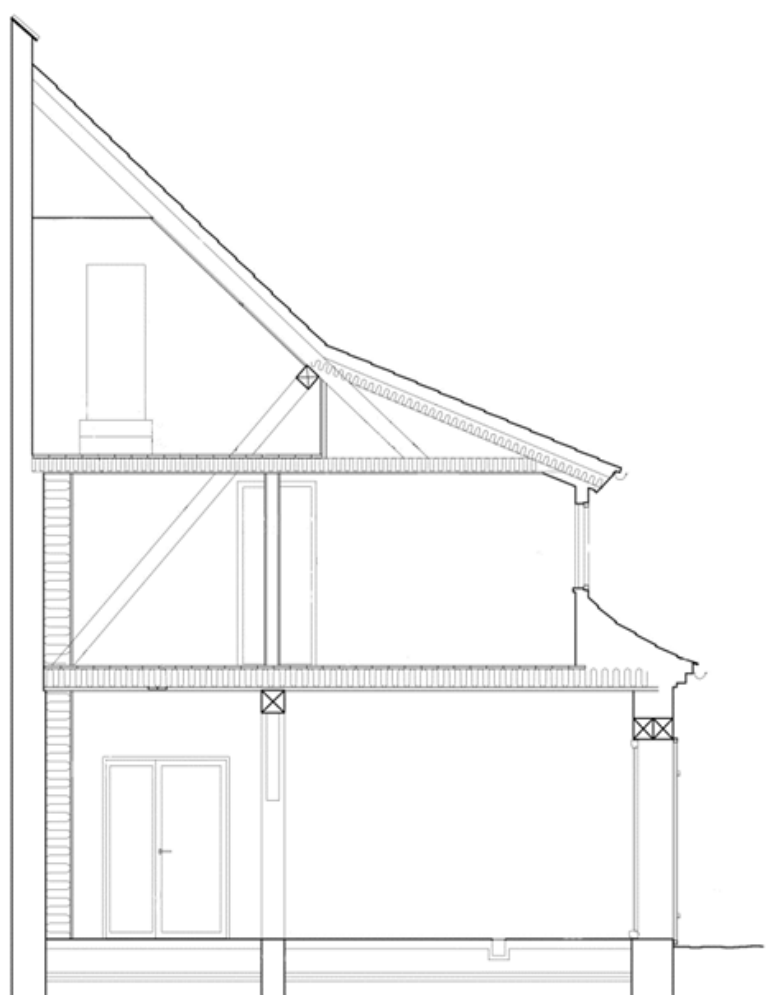

Fig. 5 Structural section of the monopitch roof building.

presence of relevant assessment authorities. The relevant assessment authorities involved in the refurbishment of Fæstningens Materialgård were:
- The Heritage Agency which had to evaluate each measure specifically for each building from a conservation and heritage point of view. Assessments were only for guidance. The final, official approval was only to be given once the entire project was submitted;

- The Danish Working Environment Authority, has had to evaluate each measure specifically in terms of the acceptability of the workspace;

- Owner/Developer who has to evaluate each measure specifically for each building from the owner's perspective. The impact of each measure was evaluated in relation to cost-benefit, rental opportunities, operation and maintenance;

- Architects who had to evaluate each measure specifically for each building from an architectural point of view. Among other issues, the form, appearance, functionality and interior design were evaluated. These evaluations were further supplemented wherever possible with more general assessments and views;

- Structural engineers who had to evaluate each measure specifically for each building from a structural design perspective. The impact of each measure on the existing construction was risk assessed, especially with respect to building physics, i.e., moisture levels. Wherever possible, a more general assessment of the individual measures was given with references to relevant literature;

- HVAC (Heating, Ventilation and Air Conditioning) engineers, who had to evaluate each measure specifically for each building from an energy and indoor climate point of view. The impact of the measure in terms of energy-saving effect and room temperature was critically evaluated. Wherever possible, a more general assessment of the measure was given, with references to relevant literature.

The process identified feasible refurbishment measures, shown sketched in Fig. 6, that can reduce the energy consumption of the listed complex included a number of terms such as: 


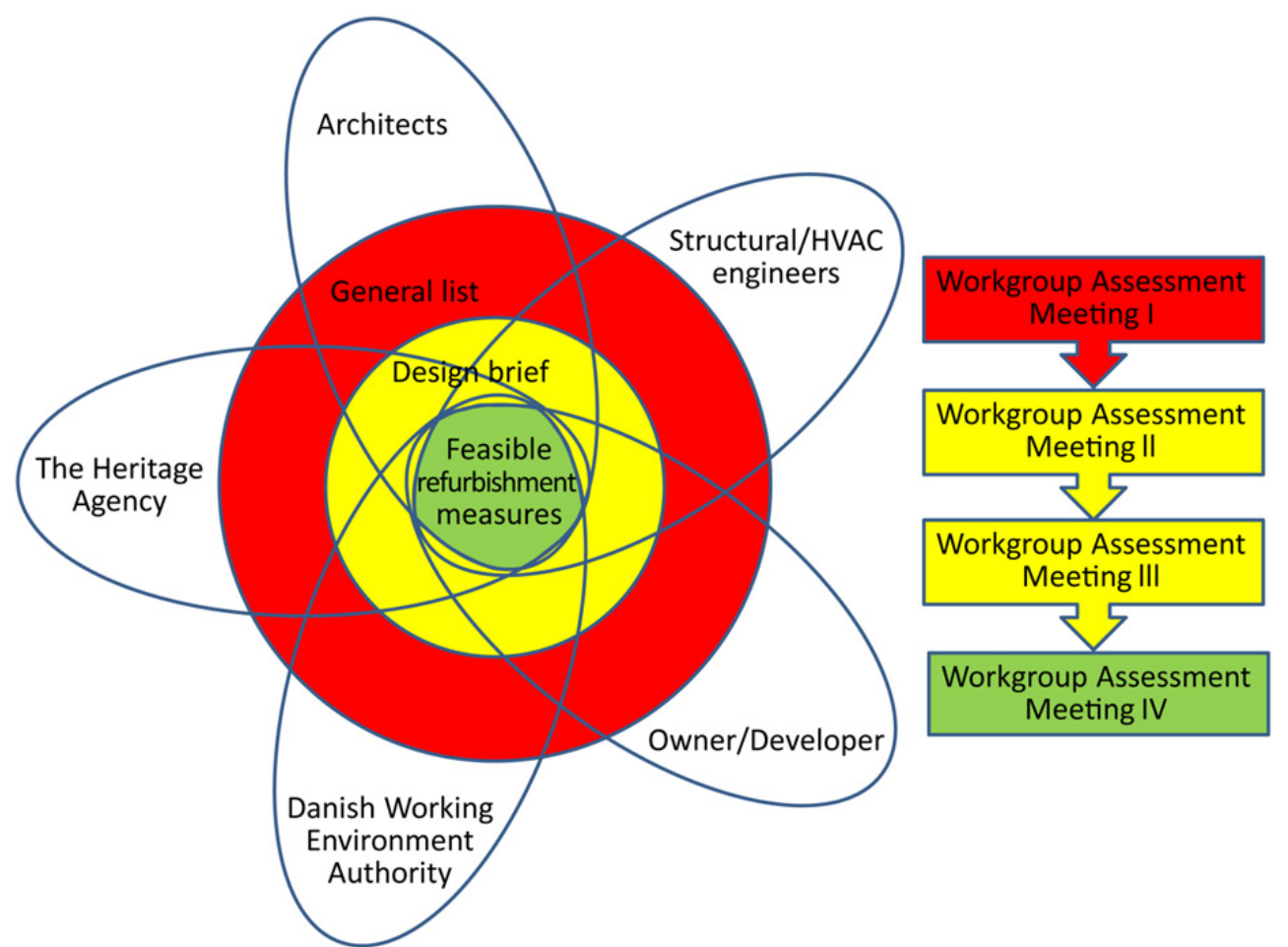

Fig. 6 A sketch of the process for cooperation between the parties involved in identifying feasible refurbishment measures for the refurbishment of Fæstningens Materialgård a heritage complex.

- Feasible refurbishment measures: The identified refurbishment measures that fulfill the requirement of creating synergy between the interests of preserving heritage values and developing reasonable cost-benefit solutions that meets the requirements for the future use of the building;

- Design brief: A construction brief elaborated and needed to form the basis for choosing feasible refurbishment measures and to carry out energy evaluation calculations. The brief was to include: building history, current condition of the construction and individual building materials and identified heritage values connected with the individual buildings and the listed complex;

- General list: A list of all the potential energy-saving measures that needs to be considered in connection with the refurbishment of any building and any group of buildings. Measures such as windows, double glazing, solar screening, solar shading, added insulation of outer walls, added insulation at ceilings and ground slab, air tightness, heat pump, light bulbs, daylight control, central heating and cooling system, power supply, ground heating source, central technical system controlling electricity, air exchange, domestic hot water supply, rain water collection, solar panels, photovoltaics, heat emission, ventilation, use of room and so on. It was important that the general list initially contained a comprehensive list of refurbishment measures that could be used in connection with energy-upgrading. As a starting point, the list should be elaborated to include all energy-upgrading measures regardless of the architectural and heritage value of the buildings. The proposals should not take into account the location, actual building geometry, costs, use and function of the building or similar features that could immediately mean that the proposed measures were not to be implemented. The general list was prepared in order to consider all available measures as broadly as possible.

For the individual measures to reach the level of feasible refurbishment measures, measures were carefully evaluated. For each of the energy-saving 
measure on the general list, an assessment scheme was made. The scheme was used to evaluate and keep track of the evaluation made of every initiative and as a reminder of why/why not the energy-saving measure was/was not recommended for further development through the process.

Measures that were not feasible were removed from the general list and a project-specific list was elaborated. A measure may have been removed from the general list, of optional measures, for many reasons, for example due to conservation interests or due to architectural, structural and/or indoor climate issues, etc.. An info sheet was prepared for all measures entered on the project specific list. The info sheet was prepared in order to quantify the scope of each measure and to estimate the energy-saving potential. A simple pay-back time and the expected $\mathrm{CO}_{2}$ savings were estimated and used for the cost-benefit analysis.

For the entire project submitted quality levels of indoor climate conditions in primary rooms, as well as being able to describe a desired future level, the standard EN ISO 7730 [3] was to be implemented as the building was to be used as an office building. Furthermore, HVAC and indoor climate requirements were to be addressed.

Feasible refurbishment measures were found from a series of workgroup assessment meetings. Four workgroup assessment meetings were held:

- Workgroup Assessment Meeting I roughly sorted the measures on the general list. All the project team members made an overall assessment. Thus, each general list proposal could be subjected to a first interdisciplinary evaluation. Based on the first overall assessment, an upgraded general list of proposals suitable for further work was produced;

- Prior to Workgroup Assessment Meeting II, the existing readings of the consumption of domestic hot water, heating and electricity, was used to produce an estimated overview of how the existing consumption of heat loss, hot water supply and electricity were distributed and consumed in the building.

At this time, the building was entered into a model using a simulation program for, indoor climate evaluation and energy consumption, measurement and evaluation. The individual buildings in the listed complex were entered with their existing components, construction, floor areas and their orientation. The simulation model was supplied with the existing consumption data from use and lighting systems. The simulation model provided an opportunity to see the energy consumption distributed on the individual building components, but could also be used to get an idea of the thermal indoor climate in the different buildings, areas, floors and rooms.

The info sheets was provided with the calculated figures and further elaborated for energy-saving proposals on the general list that, based on the first evaluation, were recommended for further development. The info sheets include the scope of each measure and its estimated effect on future consumption.

The result of Workgroup Assessment Meetings II was to create a more detailed description of the energy-saving proposals, as well as the impact of the proposed refurbishment measures on the energy consumption, $\mathrm{CO}_{2}$ savings and their effect on the indoor climate. Results were also entered on the project-specific list;

- Workgroup Assessment Meeting III was based on the results of Workgroup Assessment Meeting II. Each energy-saving proposal on the project-specific list was to be evaluated and considered in detail.

Workgroup Assessment Meeting III was held in order to make a solution-specific selection of energy-saving measures that created synergy and that was reasonable in relation to the requirements for the interior layout;

- Workgroup Assessment Meeting IV was held to go through and correct the adopted measures, in case the measures did not create synergy or did not meet the overall expectations nor lead to the expected 
effects on $\mathrm{CO}_{2}$ reduction, energy savings and indoor climate.

A sketch of the process of selecting feasible refurbishment measures through a row of workgroup assessment meeting is shown in Fig. 6.

\section{Results}

Individual feasible refurbishment measures were found for the restoration and energy upgrading of each of the individual buildings in the listed complex. Photos of the refurbished Fæstningens Materialgård are shown in Figs. 7 and 8.

For the building with the supervisor's residence, the process resulted in the agreement of 11 feasible measures for energy upgrading including low-energy glazing $-3 \mathrm{~mm}$ glass set into the existing secondary frames, building envelope air permeability $\left(0.5 \mathrm{~h}^{-1}\right.$ in the basement, $0.2 \mathrm{~h}^{-1}$ on the ground floor and $0.2 \mathrm{~h}^{-1}$ at the first floor), ventilation via opening of windows, combined heating/cooling unit designed so that it looked

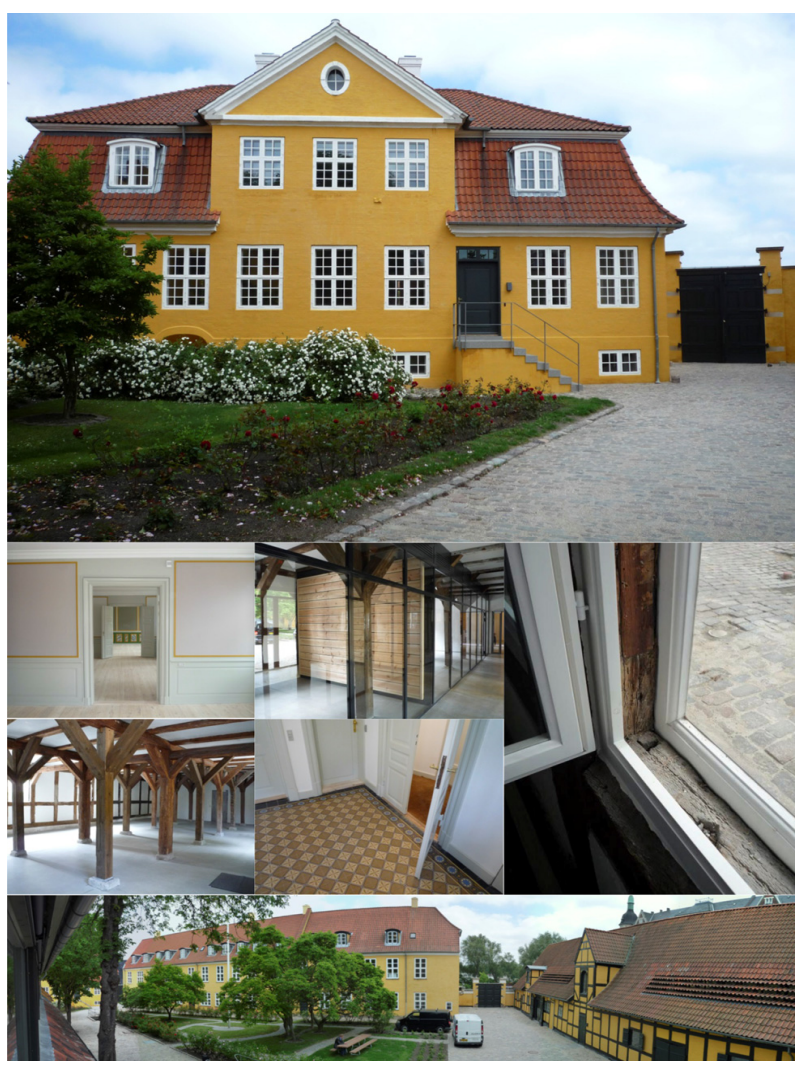

Fig. 7 Photos of the refurbished listed complex, Fæstningens Materialgård. like a flat panel radiator, cooling via a centrally placed unit where excess heat is transferred to the outside air, centralized domestic hot water supply, energy-saving light sources, daylight-controlled lighting, centralized control of electrical components, shared canteen, shared meeting and conference facilities.

For the half-timbered building, the process resulted in agreement on fifteen feasible measures for energy upgrading including new windows with low-energy glazing in new window openings, low-energy glazing in the existing secondary frames where possible, additional insulation of external walls in the kitchen area and in the utility rooms, insulated new ground slab, building envelope air permeability $\left(0.5 \mathrm{~h}^{-1}\right.$ on the ground floor and $0.16 \mathrm{~h}^{-1}$ at the first floor), balanced ventilation with a base exchange rate of $12 \mathrm{~L} / \mathrm{s}$ per person including cooling, cooling via a centrally placed unit where excess heat is transferred to the outside air, radiator heating at the first floor, underfloor heating on the ground floor, decentralized

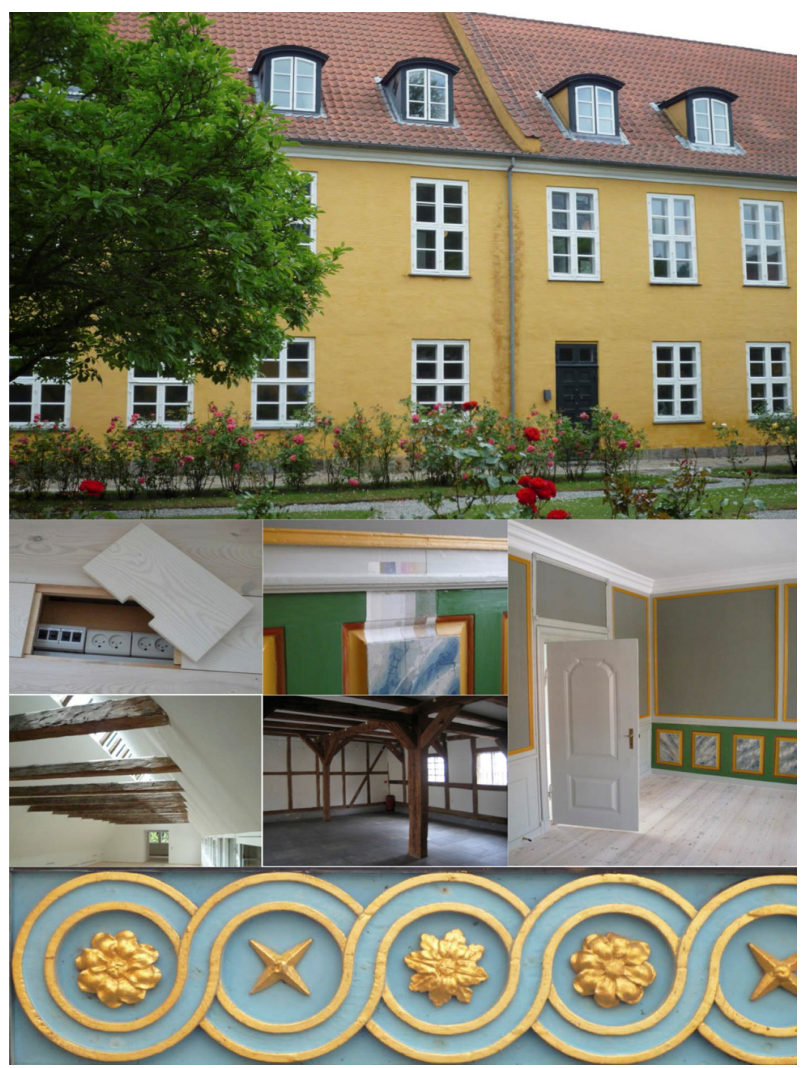

Fig. 8 Photos of the refurbished listed complex, Fæstningens Materialgård. 
domestic hot water supply, energy-saving light sources, daylight-controlled lighting, centralized control of electrical components, shared canteen, shared meeting and conference facilities.

For the office building, the process resulted in agreement on eleven feasible measures for energy upgrading including low-energy glazing $-3 \mathrm{~mm}$ glass set into the existing secondary frames, building envelope air permeability $\left(0.29 \mathrm{~h}^{-1}\right.$ on the ground floor, $0.2 \mathrm{~h}^{-1}$ at the first floor and $0.2 \mathrm{~h}^{-1}$ on the second floor), ventilation by opening windows, combined heating/cooling unit designed so that it looked like a flat panel radiator, cooling via a centrally placed unit where excess heat is transferred to the outside air, decentralized domestic hot water production, energy-saving light sources, daylight-controlled lighting, centralized control of electrical components, shared canteen, shared meeting and conference facilities.

For the monopitch roof building, the process resulted in agreement on seventeen feasible measures for energy upgrading including replacement of windows that are not original with new windows with low- energy glazing, new low energy windows in new window openings (re-established gateways), low-energy glazing in the existing secondary frames, external solar shading with a reduction factor of 0.5 , added internal insulation of external walls in some areas, adding insulation of the ground slab, building envelope air permeability $\left(0.35 \mathrm{~h}^{-1}\right.$ on the ground floor, $0.17 \mathrm{~h}^{-1}$ at the first floor), balanced ventilation with a base exchange rate of approximately $12 \mathrm{~L} / \mathrm{s}$ per person (including cooling), cooling via a centrally placed unit where excess heat is transferred to the outside air, radiator heating at the first floor, underfloor heating of the ground floor, decentralized domestic hot water production, energy-saving light sources, daylight-controlled lighting, centralized control of electrical components, shared canteen, shared meeting and conference facilities.

Calculations of the whole refurbished listed complex showed an overall $\mathrm{CO}_{2}$ reduction of $18 \%$. The energy used to achieve an acceptable workspace with a thermal indoor climate level of Category C [3], was seen to result in a far less total $\mathrm{CO}_{2}$ reduction, calculated to be $7.8 \%$. However, the indoor climate level was raised from an unacceptable level to an acceptable level, and rearranging the layout made room for another 40 workstations.

\section{Discussion}

A process for selecting feasible comprehensive refurbishment measures, including energy-upgrading measures for heritage buildings, has been described. In addition, the end result was shown for the restoration and refurbishment of Fæstningens Materialgård, a listed complex. The study shows how the cooperation between authorities and the owner of a heritage building can be formalized and described by a process that can lead to the identification and implementation of feasible measures for refurbishment, including energy upgrading, and still be able to preserve identified heritage values attached to a listed building or a listed complex. Using the process of cooperation, individual feasible refurbishment measures were found for the refurbishment including restoration and energy upgrading of each of the individual buildings included in the listed complex Fæstningens Materialgård. Calculations of the whole refurbished listed complex showed an overall $\mathrm{CO}_{2}$ reduction of $7.8 \%$, achieving an acceptable workspace environment with a thermal indoor climate level of Category C [3]. The indoor climate level was raised from an unacceptable level to an acceptable level, and rearranging the layout made room for another 40 workstations.

Heritage buildings include listed buildings as well as less protected buildings, which however has values worth preserving can benefit from the described process for cooperation between authorities and the owner, to identify and implement feasible refurbishments. The decision-making processes 
related to refurbishment of listed buildings in Denmark are carried out in cooperation/dialogue with the Heritage Agency. The Heritage Agency possesses the expertise and has to agree to nearly all issues. The Heritage Agency is an agency under the Ministry of Culture, which has the overall responsibility of managing Denmark's cultural heritage. The agency is an authority on listed buildings and the conservation of historic and archaeological relics.

The process of refurbishing Fæstningens Materialgård consisted of a series of meetings, between the authorities and the owner of the listed complex, with the aim of identifying feasible, refurbishment measures to be implemented. The authorities were represented both by the Heritage Agency and the Danish Working Environment Authority. In general, each specific case might need expertise from a different set of experts and authorities. Fig. 6 shows a sketch of the process used to identify feasible refurbishment measures. Figs. 7 and 8 show photos of the refurbished Fæstningens Materialgård [4].

\section{Conclusions}

Denmark has carried out a number of case studies of comprehensive refurbishment projects including energy upgrading of heritage buildings. These case studies demonstrate that a process for cooperation between the authorities and the owner of a heritage building on the implementation of feasible measures is needed when carrying out refurbishment, including energy upgrading, when preserving heritage buildings.

Heritage buildings can include listed buildings as well as less protected buildings, however with values worth preserving. In principle, the process for cooperation between the authorities and the owner of a heritage building can be used for all heritage buildings to identify and implement feasible refurbishments, including carrying out energy upgrading.

The process describing the selection of feasible measures for refurbishing the listed complex, Fæstningens Materialgård, includes the process of:

- how to tackle restoration of a listed building;

- how to compose and organize an interdisciplinary workgroup consisting of the building owner, the authorities, the architects and the engineers;

- how to evaluate the individual measure for reducing the energy consumption.

The refurbishment process consisted of a series of meetings held with the aim of identifying feasible refurbishment measures that it was acceptable to implement hence to restore and achieve a reduction of the energy consumption of the listed complex. Every process was gathered around a body of decision-making meetings called the workgroup assessment meetings. Following the described process has led to a comprehensive refurbishment of the listed complex without compromising the core heritage values. Furthermore, it was demonstrated that it is possible to integrate design, supply routes and energy savings by devising different solutions that together produce energy savings, combined with the creation of an indoor climate level of Category $\mathrm{C}$ [3], which fulfills the requirements in the current Danish Building Regulations and by the Danish Working Environment Authority for the design of permanent workplaces.

Today Fæstningens Materialgård, is a listed building complex used for renting out offices including shared facilities like meeting and conference facilities, canteen, energy and cooling supply plants systems. Appointments to visit the site can be arranged through the owner, Realdania.

\section{Acknowledgments}

The work on which this paper is based was supported by the Priority 1: Fostering Innovations of the Baltic Sea Region Programme 2007-2013. Climate Change, Cultural Heritage \& Energy Efficient Monuments, Co2olBricks [4]. Furthermore, Realdania 
has been very helpful in sharing experience to identify feasible refurbishment measures for the listed complex Fæstningens Materialgård. Realdania purchases historic buildings that serve "the common good". It is their goal to develop and to preserve properties of historic value.

\section{References}

[1] SAVE (Survey of Architectural Values in the Environment) method, InterSAVE Home Page, http://www.sns.dk/byer-byg/Netpub/INTRSAVE/TEKST /CONTENTS.HTM (accessed Oct. 20, 2013).
[2] The Consolidated Listed Buildings and Preservation of Buildings and Urban Environments Act No. 1088 Home Page, http://www.kulturarv.dk/fileadmin/user_upload/ kulturarv/english/The_Consolidated_Act_No._1088_on_ Listed_Buildings_and_Preservation_of_Buildings_and_U rban_Environments.pdf (accessed Oct. 20, 2013).

[3] EN ISO 7730, Ergonomics of the Thermal Environment-Analytical Determination and Interpretation of Thermal Comfort Using Calculation of the PMV and PPD Indices and Local Thermal Comfort Criteria, 2005.

[4] Climate Change, Cultural Heritage \& Energy Efficient Monuments, Co2olBricks Home Page, http://www.coolbricks.eu/index.php?id=115 (accessed Oct. 20, 2013). 